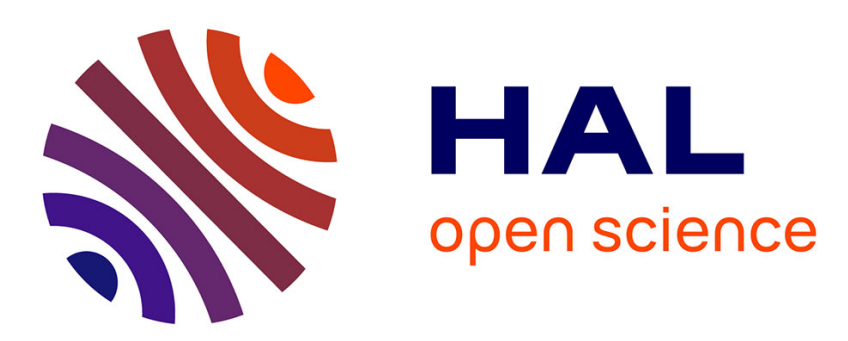

\title{
Numerical and analytical scale-transition prediction of hygro-mechanical stresses in multidirectional carbon-epoxy laminates
}

\author{
Sylvain Fréour, Frédéric Jacquemin, Ronald Guillén
}

\section{- To cite this version:}

Sylvain Fréour, Frédéric Jacquemin, Ronald Guillén. Numerical and analytical scale-transition prediction of hygro-mechanical stresses in multidirectional carbon-epoxy laminates. Materials Science

Forum, 2006, 524-525, pp.439-444. hal-01007122

\section{HAL Id: hal-01007122 \\ https://hal.science/hal-01007122}

Submitted on 25 Oct 2017

HAL is a multi-disciplinary open access archive for the deposit and dissemination of scientific research documents, whether they are published or not. The documents may come from teaching and research institutions in France or abroad, or from public or private research centers.
L'archive ouverte pluridisciplinaire HAL, est destinée au dépôt et à la diffusion de documents scientifiques de niveau recherche, publiés ou non, émanant des établissements d'enseignement et de recherche français ou étrangers, des laboratoires publics ou privés. 


\title{
Numerical and analytical scale-transition prediction of hygro- mechanical stresses in multidirectional carbon-epoxy laminates
}

\author{
Fréour $S{ }^{a}$, Jacquemin F. ${ }^{b}$, Guillén $\mathrm{R}^{\mathrm{c}}{ }^{\mathrm{c}}$ \\ Institut de Recherche en Génie Civil et Mécanique (UMR CNRS 6183), \\ IUT de Saint-Nazaire - Université de Nantes, \\ 37, Boulevard de 1'Université, BP 406, 44602 Saint-Nazaire cedex, France. \\ a sylvain.freour@univ-nantes.fr ; ${ }^{b}$ frederic.jacquemin@univ-nantes.fr ; \\ ${ }^{\mathrm{c}}$ ronald.guillen@univ-nantes.fr
}

Keywords: self-consistent model; analytical approach; hygro-elastic stresses.

\section{Introduction}

Moisture diffusion within an epoxy matrix based composite structure exposed to humid environmental conditions induces two types of internal stresses: the macroscopic stresses (at the scale of the composite plies) and the microscopic stresses (experienced by the elementary constituents of a considered ply). Macroscopic stresses induced by gradients of moisture concentration and/or the heterogeneity of the coefficients of moisture expansion are determined using continuum mechanics classical formalism. This method enables taking into account both space and time effects on moisture diffusion in the composite structure [1]. Localization of the macroscopic mechanical states at microscopic scale lead to different stresses in the matrix and the fiber. The discrepancies come from the strong heterogeneities of elastic properties, coefficients of moisture expansion and moisture content of the composite plies constituents. Scale transition models are often used in order to achieve the localization procedure.

In the present work, a self-consistent hygro-elastic model, based on Eshelby [2] and Kröner [3] pioneering papers, is developed in order to determine the microscopic mechanical states in a composite ply. This model takes into account the microstructure of the constituents (in particular, the reinforcing fibers morphology) and the heterogeneous microscopic moisture content (actually the reinforcing carbon fibers do not absorb moisture, which is consequently concentrated in the polymer matrix). Both the classical purely numerical approach and a rigorous fully analytical treatment of the question are respectively achieved in sections 2 and 3. Section 4 compares the closed-form solution to the fully numerical self-consistent model for various geometrical arrangements of the fibers: uni-directional or laminated composites.

\section{Hygro-elastic micromechanical model}

2.1 Self-Consistent estimates for hygro-elastic properties. A self-consistent model based on Kröner [3] and Eshelby [2] hypotheses is extended to the hygroscopic loading of composite materials in order to determine localization of the stresses in the constituents of each ply: the matrix and the fiber. The material is investigated at two different scales for the needs of micromechanical modeling: a) the average behavior of a ply, defines the macroscopic scale, denoted by the superscript ${ }^{1}$ b) the properties and mechanical states of the matrix and fiber are respectively indicated by the superscripts ${ }^{\mathrm{m}}$ and ${ }^{\mathrm{f}}$. These constituents define the microscopic scale of the material. The hygro-elastic behaviour of the material satisfies:

$$
\sigma^{\alpha}=\mathbf{L}^{\alpha}:\left(\varepsilon^{\alpha}-\beta^{\alpha} \Delta C^{\alpha}\right)
$$

where $\alpha$ replaces the superscripts ${ }^{\mathrm{I}},{ }^{\mathrm{f}}$ or ${ }^{\mathrm{m}}$. $\mathbf{L}$ stands for elastic stiffness tensor, whereas $\boldsymbol{\beta}$ are the Coefficients of Moisture Expansion (CME) and $\Delta \mathrm{C}$ the moisture content.

According to Hill [4], macroscopic stresses and strains can be determined through the volume average of the microscopic stresses and strains: 


$$
\left\langle\sigma^{\alpha}\right\rangle_{\alpha=f, m}=\sigma^{\mathbf{I}}, \quad\left\langle\varepsilon^{\alpha}\right\rangle_{\alpha=f, m}=\varepsilon^{\mathbf{I}}
$$

In a previous work [5], the authors achieved to obtain the following relation for the macroscopic elastic properties (Eq. 3) and coefficient of moisture expansion (Eq. 4) of the composite, assuming that the fibers do not absorb water $\left(\Delta \mathrm{C}^{\mathrm{f}}=0\right)$ :

$$
\begin{aligned}
& \mathbf{L}^{\mathbf{I}}=\left\langle\left(\mathbf{L}^{\alpha}+\mathbf{L}^{\mathbf{I}}: \mathbf{R}^{\mathbf{I}}\right)^{-1}:\left(\mathbf{L}^{\mathbf{I}}+\mathbf{L}^{\mathbf{I}}: \mathbf{R}^{\mathbf{I}}\right): \mathbf{L}^{\alpha}\right\rangle_{\alpha=f, \mathrm{~m}}, \\
& \boldsymbol{\beta}^{\mathbf{I}}=\frac{\rho^{\mathrm{I}}}{\rho^{\mathrm{m}}} \mathbf{L}^{\mathbf{L}^{-1}}\left\langle\left(\mathbf{L}^{\alpha}+\mathbf{L}^{\mathbf{I}}: \mathbf{R}^{\mathbf{I}}\right)^{-1}\right\rangle_{\alpha=f, \mathrm{~m}}^{-1}:\left(\mathbf{L}^{\mathbf{m}}+\mathbf{L}^{\mathbf{I}}: \mathbf{R}^{\mathrm{I}}\right)^{-1}: \mathbf{L}^{\mathbf{m}}: \boldsymbol{\beta}^{\mathbf{m}},
\end{aligned}
$$

where $\rho^{\mathrm{I}}$ and $\rho^{\mathrm{m}}$ are respectively the composite and resin densities. $\mathbf{R}^{\mathbf{I}}$ is the reaction tensor, defined by Eshelby in [2].

2.2 Microscopic mechanical states. Since the carbon fiber does not absorb water, the stress-strain relation (Eq. 1) rewrites:

$$
\sigma^{f}=L^{f}: \varepsilon^{f}
$$

In that case, Eshelby's formalism (see [2]) lead to the following scale transition relation for the microscopic strains experienced by the fibers:

$$
\varepsilon^{\mathbf{f}}=\left(\mathbf{L}^{\mathbf{f}}+\mathbf{L}^{\mathbf{I}}: \mathbf{R}^{\mathbf{I}}\right)^{-1}:\left[\left(\mathbf{L}^{\mathbf{I}}+\mathbf{L}^{\mathbf{I}}: \mathbf{R}^{\mathbf{I}}\right): \varepsilon^{\mathbf{I}}-\mathbf{L}^{\mathbf{I}}: \boldsymbol{\beta}^{\mathbf{I}} \Delta \mathbf{C}^{\mathbf{I}}\right]
$$

Eq. 6 enables to determine the microscopic strain in the fiber from the macroscopic strains. Thereafter, Eq. 5 is used in order to find the fiber stresses. The microscopic mechanical states experienced by the matrix are thereafter deduced from Hill volume averages (Eq. 2).

\section{Towards analytical expressions of the microscopic hygro-mechanical states}

3.1 Closed-forms solution of Morris' tensor for fiber morphology. The self-consistent framework is based on the mechanical treatment of the interactions between ellipsoidal heterogeneous inclusions and the embedding homogeneous equivalent medium. The average macroscopic elastic properties $\mathbf{L}^{\mathbf{I}}$ of the composite are related to the morphology assumed for elementary inclusions, through Morris' tensor $\mathbf{E}^{\mathbf{I}}$. Actually, the reaction tensor $\mathbf{R}^{\mathbf{I}}$ introduced in Eq. 3 writes:

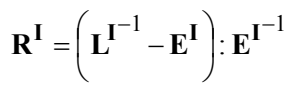

Originally, spherical inclusions only were considered by Morris [6]. For ellipsoidal shaped inclusions Asaro and Barnett [7] and Kocks et al. [8] have established the following relations for numerical calculation of each ${ }_{\mathrm{ijkl}}$ subscripted component of Morris' tensor:

$$
\mathrm{E}_{\mathrm{ijkl}}^{\mathrm{I}}=\frac{1}{4 \pi} \int_{0}^{\pi} \sin \theta \mathrm{d} \theta \int_{0}^{2 \pi} \gamma_{\mathrm{ikjl}} \mathrm{d} \varphi \quad \text { where } \quad \gamma_{\mathrm{ikjl}}=\mathrm{K}_{\mathrm{ik}}^{-1}(\xi) \xi_{\mathrm{j}} \xi_{1} \text {. }
$$

Some analytical forms for Morris' tensor are available in the literature; the interested reader can for instance refer to [8-10]. Nevertheless, these forms were established considering either spherical, disc-shaped of fiber-shaped inclusions embedded in an ideally isotropic macroscopic medium, that is incompatible with the strong elastic anisotropy exhibited by fiber-reinforced composites at 
macroscopic scale. In the case of fiber-reinforced composites, a transversely isotropic macroscopic elastic behaviour being coherent with fiber shape is actually expected (and predicted by the numerical computations). This is compatible with the following form of $\mathbf{K}$ tensor:

$$
\mathbf{K}=\left[\begin{array}{lcc}
\mathrm{L}_{55}^{\mathrm{I}}\left(\xi_{2}^{2}+\xi_{3}^{2}\right) & \left(\mathrm{L}_{12}^{\mathrm{I}}+\mathrm{L}_{55}^{\mathrm{I}}\right) \xi_{1} \xi_{2} & \left(\mathrm{~L}_{12}^{\mathrm{I}}+\mathrm{L}_{55}^{\mathrm{I}}\right) \xi_{1} \xi_{2} \\
\left(\mathrm{~L}_{12}^{\mathrm{I}}+\mathrm{L}_{55}^{\mathrm{I}}\right) \xi_{1} \xi_{2} & \mathrm{~L}_{22}^{\mathrm{I}} \xi_{2}^{2}+\mathrm{L}_{44}^{\mathrm{I}} \xi_{3}^{2} & \left(\mathrm{~L}_{23}^{\mathrm{I}}+\mathrm{L}_{44}^{\mathrm{I}}\right) \xi_{2} \xi_{3} \\
\left(\mathrm{~L}_{12}^{\mathrm{I}}+\mathrm{L}_{55}^{\mathrm{I}}\right) \xi_{1} \xi_{2} & \left(\mathrm{~L}_{23}^{\mathrm{I}}+\mathrm{L}_{44}^{\mathrm{I}}\right) \xi_{2} \xi_{3} & \mathrm{~L}_{44}^{\mathrm{I}} \xi_{2}^{2}+\mathrm{L}_{22}^{\mathrm{I}} \xi_{3}^{2}
\end{array}\right]
$$

where $\xi_{1}=\frac{\sin \theta \cos \varphi}{a_{1}}, \xi_{2}=\frac{\sin \theta \sin \varphi}{a_{2}}, \xi_{3}=\frac{\cos \theta}{a_{3}}$. Assuming that the longitudinal (subscripted ${ }_{1}$ ) axis is parallel to fiber axis, one obtains the following conditions for the semi-lengths of the microstructure representative ellipsoid: $\mathrm{a}_{1} \rightarrow \infty, \mathrm{a}_{2}=\mathrm{a}_{3}$.

The determination of Morris' tensor requires the determination of the inverse of $\mathbf{K}$ tensor that is involved in the calculation of $\gamma$. Due to the listed above conditions over the dimensions $a_{1}, a_{2}$ and $\mathrm{a}_{3}$ of the considered fiber-shaped inclusions, drastic simplifications of Morris' tensor occur:

$$
\mathbf{E}^{\mathbf{I}}=\left[\begin{array}{cccccc}
0 & 0 & 0 & 0 & 0 & 0 \\
0 & \mathrm{E}_{22}^{\mathrm{I}} & \mathrm{E}_{23}^{\mathrm{I}} & 0 & 0 & 0 \\
0 & \mathrm{E}_{23}^{\mathrm{I}} & \mathrm{E}_{22}^{\mathrm{I}} & 0 & 0 & 0 \\
0 & 0 & 0 & \mathrm{E}_{44}^{\mathrm{I}} & 0 & 0 \\
0 & 0 & 0 & 0 & \mathrm{E}_{55}^{\mathrm{I}} & 0 \\
0 & 0 & 0 & 0 & 0 & \mathrm{E}_{55}^{\mathrm{I}}
\end{array}\right] \text { where, }\left\{\begin{array}{l}
\mathrm{E}_{22}^{\mathrm{I}}=\frac{3}{8 \mathrm{~L}_{22}^{\mathrm{I}}}+\frac{1}{4 \mathrm{~L}_{22}^{\mathrm{I}}-4 \mathrm{~L}_{23}^{\mathrm{I}}}, \mathrm{E}_{23}^{\mathrm{I}}=\frac{\mathrm{L}_{22}^{\mathrm{I}}+\mathrm{L}_{23}^{\mathrm{I}}}{8 \mathrm{~L}_{22}^{\mathrm{I}} \mathrm{L}_{23}^{\mathrm{I}}-8 \mathrm{~L}_{22}^{\mathrm{I}^{2}}} \\
\mathrm{E}_{44}^{\mathrm{I}}=\frac{1}{8 \mathrm{~L}_{22}^{\mathrm{I}}}+\frac{1}{4 \mathrm{~L}_{22}^{\mathrm{I}}-4 \mathrm{~L}_{23}^{\mathrm{I}}}, \mathrm{E}_{55}^{\mathrm{I}}=\frac{1}{8 \mathrm{~L}_{55}^{\mathrm{I}}}
\end{array}\right.
$$

3.2 Analytical solution for the pseudo-macroscopic mechanical states. In fact, the epoxy matrix is usually isotropic, so that three components only have to be considered for its elastic constants: $\mathrm{L}_{11}^{\mathrm{m}}, \mathrm{L}_{12}^{\mathrm{m}}$ and $\mathrm{L}_{44}^{\mathrm{m}}$. One moisture expansion coefficient is sufficient to describe the hygroscopic behaviour of the matrix: $\beta_{11}^{\mathrm{m}}$.

In the case of the carbon fibers, a transverse isotropy is generally observed. Thus, the corresponding elasticity constants depend on the following components: $\mathrm{L}_{11}^{\mathrm{f}}, \mathrm{L}_{12}^{\mathrm{f}}, \mathrm{L}_{22}^{\mathrm{f}}, \mathrm{L}_{23}^{\mathrm{f}}, \mathrm{L}_{44}^{\mathrm{f}}$, and $\mathrm{L}_{55}^{\mathrm{f}}$. Moreover, since the carbon fiber does not absorb water, its $C M E \beta_{11}^{\mathrm{f}}$ and $\beta_{22}^{\mathrm{f}}$ will not be involved in the mechanical states determination. Introducing these additional assumptions in Eqs. 2, 5-6, and taking into account the form (Eq. 11) obtained for Morris' tensor, the following general expression is found for the strain tensors experienced by the matrix:

$$
\left\{\begin{array}{l}
\varepsilon_{11}^{\mathrm{m}}=\varepsilon_{11}^{\mathrm{I}}, \quad \varepsilon_{12}^{\mathrm{m}}=\frac{2 \mathrm{~L}_{55}^{\mathrm{I}} \varepsilon_{12}^{\mathrm{I}}}{\mathrm{L}_{55}^{\mathrm{I}}+\mathrm{L}_{44}^{\mathrm{m}}}, \quad \varepsilon_{13}^{\mathrm{m}}=\frac{2 \mathrm{~L}_{55}^{\mathrm{I}} \varepsilon_{13}^{\mathrm{I}}}{\mathrm{L}_{55}^{\mathrm{I}}+\mathrm{L}_{44}^{\mathrm{m}}}, \quad \varepsilon_{22}^{\mathrm{m}}=\frac{\mathrm{N}_{1}^{\mathrm{m}}+\mathrm{N}_{2}^{\mathrm{m}}+\mathrm{N}_{3}^{\mathrm{m}}+\mathrm{N}_{4}^{\mathrm{m}}}{\mathrm{D}_{1}^{\mathrm{m}}} \\
\varepsilon_{23}^{\mathrm{m}}=\frac{2 \mathrm{~L}_{22}^{\mathrm{I}}\left(\mathrm{L}_{22}^{\mathrm{I}}-\mathrm{L}_{23}^{\mathrm{I}}\right) \varepsilon_{23}^{\mathrm{I}}}{2 \mathrm{~L}_{22}^{\mathrm{I}^{2}}+\mathrm{L}_{23}^{\mathrm{I}}\left(\mathrm{L}_{44}^{\mathrm{I}}-\mathrm{L}_{44}^{\mathrm{m}}\right)+\mathrm{L}_{22}^{\mathrm{I}}\left(3 \mathrm{~L}_{44}^{\mathrm{m}}-2 \mathrm{~L}_{23}^{\mathrm{I}}-3 \mathrm{~L}_{44}^{\mathrm{I}}\right)} \\
\varepsilon_{33}^{\mathrm{m}}=\varepsilon_{22}^{\mathrm{m}}-4 \mathrm{~L}_{22}^{\mathrm{I}} \frac{\left(\mathrm{L}_{22}^{\mathrm{I}}-\mathrm{L}_{23}^{\mathrm{I}}\right)\left(\varepsilon_{22}^{\mathrm{I}}-\varepsilon_{33}^{\mathrm{I}}\right)}{\mathrm{L}_{22}^{\mathrm{I}^{2}}+3 \mathrm{~L}_{22}^{\mathrm{I}}\left(\mathrm{L}_{11}^{\mathrm{m}}-\mathrm{L}_{12}^{\mathrm{m}}\right)-\mathrm{L}_{23}^{\mathrm{I}}\left(\mathrm{L}_{11}^{\mathrm{m}}+\mathrm{L}_{23}^{\mathrm{I}}-\mathrm{L}_{12}^{\mathrm{m}}\right)}
\end{array},\right.
$$




$$
\text { where, } \quad\left\{\begin{array}{l}
\mathrm{N}_{1}^{\mathrm{m}}=\beta_{11}^{\mathrm{m}}\left(\mathrm{L}_{11}^{\mathrm{m}}+2 \mathrm{~L}_{12}^{\mathrm{m}}\right) \Delta \mathrm{C}^{\mathrm{m}}-\left(\beta_{11}^{\mathrm{I}} \mathrm{L}_{12}^{\mathrm{I}}+\beta_{22}^{\mathrm{I}}\left(\mathrm{L}_{22}^{\mathrm{I}}+\mathrm{L}_{23}^{\mathrm{I}}\right)\right) \Delta \mathrm{C}^{\mathrm{I}} \\
\mathrm{N}_{2}^{\mathrm{m}}=\left(\mathrm{L}_{12}^{\mathrm{I}}-\mathrm{L}_{12}^{\mathrm{m}}\right) \varepsilon_{11}^{\mathrm{I}} \\
\mathrm{N}_{3}^{\mathrm{m}}=\frac{\mathrm{L}_{22}^{\mathrm{I}}\left\{\mathrm{L}_{22}^{\mathrm{I}}\left(5 \mathrm{~L}_{11}^{\mathrm{m}}-\mathrm{L}_{12}^{\mathrm{m}}+3 \mathrm{~L}_{22}^{\mathrm{I}}\right)-\mathrm{L}_{23}^{\mathrm{I}}\left(3 \mathrm{~L}_{11}^{\mathrm{m}}+\mathrm{L}_{12}^{\mathrm{m}}+4 \mathrm{~L}_{22}^{\mathrm{I}}\right)+\mathrm{L}_{23}^{\mathrm{I}^{2}}\right\}}{\left(3 \mathrm{~L}_{22}^{\mathrm{I}}-\mathrm{L}_{23}^{\mathrm{I}}\right)\left(\mathrm{L}_{11}^{\mathrm{m}}-\mathrm{L}_{12}^{\mathrm{m}}\right)+\mathrm{L}_{22}^{\mathrm{I}^{2}}-\mathrm{L}_{23}^{\mathrm{I}^{2}}} \varepsilon_{22}^{\mathrm{I}} \\
\mathrm{N}_{4}^{\mathrm{m}}=\frac{\mathrm{L}_{22}^{\mathrm{I}}\left\{\mathrm{L}_{22}^{\mathrm{I}}\left(\mathrm{L}_{11}^{\mathrm{m}}-5 \mathrm{~L}_{12}^{\mathrm{m}}-\mathrm{L}_{22}^{\mathrm{I}}\right)+\mathrm{L}_{23}^{\mathrm{I}}\left(\mathrm{L}_{11}^{\mathrm{m}}+3 \mathrm{~L}_{12}^{\mathrm{m}}+4 \mathrm{~L}_{22}^{\mathrm{I}}\right)-3 \mathrm{~L}_{23}^{\mathrm{I}^{2}}\right\}}{\left(3 \mathrm{~L}_{22}^{\mathrm{I}}-\mathrm{L}_{23}^{\mathrm{I}}\right)\left(\mathrm{L}_{11}^{\mathrm{m}}-\mathrm{L}_{12}^{\mathrm{m}}\right)+\mathrm{L}_{22}^{\mathrm{L}^{2}}-\mathrm{L}_{23}^{\mathrm{I}^{2}}} \varepsilon_{33}^{\mathrm{I}} \\
\mathrm{D}_{1}^{\mathrm{m}}=\mathrm{L}_{11}^{\mathrm{m}}+\mathrm{L}_{12}^{\mathrm{m}}+\mathrm{L}_{22}^{\mathrm{I}}-\mathrm{L}_{23}^{\mathrm{I}}
\end{array}\right.
$$

The corresponding analytical form for the microscopic stress tensor in the matrix comes from Eq. 1:

$$
\boldsymbol{\sigma}^{\mathbf{m}}=\left[\begin{array}{ccc}
\sigma_{11}^{\mathrm{m}} & 2 \mathrm{~L}_{44}^{\mathrm{m}} \varepsilon_{12}^{\mathrm{m}} & 2 \mathrm{~L}_{44}^{\mathrm{m}} \varepsilon_{13}^{\mathrm{m}} \\
2 \mathrm{~L}_{44}^{\mathrm{m}} \varepsilon_{12}^{\mathrm{m}} & \sigma_{22}^{\mathrm{m}} & 2 \mathrm{~L}_{44}^{\mathrm{m}} \varepsilon_{23}^{\mathrm{m}} \\
2 \mathrm{~L}_{44}^{\mathrm{m}} \varepsilon_{13}^{\mathrm{m}} & 2 \mathrm{~L}_{44}^{\mathrm{m}} \varepsilon_{23}^{\mathrm{m}} & \sigma_{33}^{\mathrm{m}}
\end{array}\right] \text { with, }\left\{\begin{array}{l}
\sigma_{11}^{\mathrm{m}}=\mathrm{L}_{11}^{\mathrm{m}} \varepsilon_{11}^{\mathrm{m}}+\mathrm{L}_{12}^{\mathrm{m}}\left(\varepsilon_{22}^{\mathrm{m}}+\varepsilon_{33}^{\mathrm{m}}\right)-\beta_{11}^{\mathrm{m}}\left(\mathrm{L}_{11}^{\mathrm{m}}+2 \mathrm{~L}_{12}^{\mathrm{m}}\right) \Delta \mathrm{C}^{\mathrm{m}} \\
\sigma_{22}^{\mathrm{m}}=\mathrm{L}_{11}^{\mathrm{m}} \varepsilon_{22}^{\mathrm{m}}+\mathrm{L}_{12}^{\mathrm{m}}\left(\varepsilon_{11}^{\mathrm{m}}+\varepsilon_{33}^{\mathrm{m}}\right)-\beta_{11}^{\mathrm{m}}\left(\mathrm{L}_{11}^{\mathrm{m}}+2 \mathrm{~L}_{12}^{\mathrm{m}}\right) \Delta \mathrm{C}^{\mathrm{m}} . \\
\sigma_{33}^{\mathrm{m}}=\mathrm{L}_{11}^{\mathrm{m}} \varepsilon_{33}^{\mathrm{m}}+\mathrm{L}_{12}^{\mathrm{m}}\left(\varepsilon_{11}^{\mathrm{m}}+\varepsilon_{22}^{\mathrm{m}}\right)-\beta_{11}^{\mathrm{m}}\left(\mathrm{L}_{11}^{\mathrm{m}}+2 \mathrm{~L}_{12}^{\mathrm{m}}\right) \Delta \mathrm{C}^{\mathrm{m}}
\end{array}\right.
$$

The local mechanical states in the fiber are provided by Hill's average laws (Eq 2.).

\section{Comparison between the analytical and the numerical self-consistent models}

4.1 Introduction. Thin laminated composite pipes, with thickness $4 \mathrm{~mm}$, initially dry then exposed to an ambient fluid, made up of T300/5208 carbon-epoxy plies are considered for the determination of both macroscopic stresses and moisture content as a function of time and space. Table 1 presents the elastic properties considered for the T300 carbon fiber, N5208 epoxy matrix and the effective stiffness deduced from the self-consistent approach for a fiber volume fraction of $60 \%$ in the composite ply. The coefficients of moisture expansion obtained through the same approach are : $\beta_{11}^{\mathrm{I}}=0.035$ and $\beta_{22}^{\mathrm{I}}=1.026\left(\beta_{11}^{\mathrm{m}}=0.6\right)$.

\begin{tabular}{lccccc}
\cline { 2 - 6 } & $\mathrm{E}_{1}[\mathrm{GPa}]$ & $\mathrm{E}_{2}, \mathrm{E}_{3}[\mathrm{GPa}]$ & $v_{12}, v_{13}$ & $\mathrm{G}_{23}[\mathrm{GPa}]$ & $\mathrm{G}_{12}[\mathrm{GPa}]$ \\
\hline T300 fibers & 230 & 15 & 0.2 & 7 & 15 \\
\hline N 5208 epoxy matrix & 4.5 & 4.5 & 0.4 & 1.6 & 1.6 \\
\hline T300/5208 composite & 139.6 & 9.8 & 0.28 & 3.5 & 6.4 \\
\hline
\end{tabular}

Table 1: Microscopic and macroscopic mechanical properties

4.2 Results - checking of the analytical model.

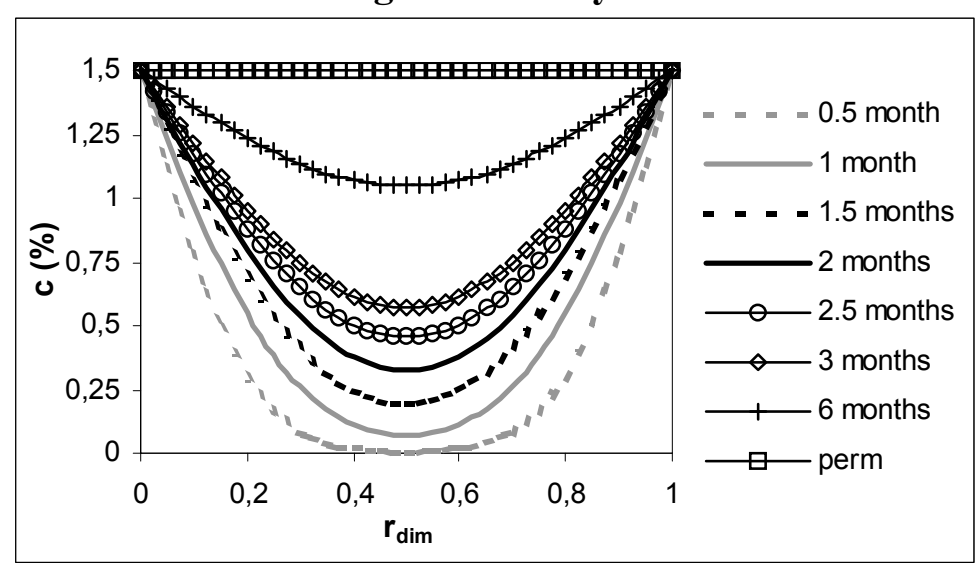

Figure 1. Concentration profiles in T300/5208
Figure 1 shows the time-dependent concentration profiles, resulting from the application of a boundary concentration $c_{0}$, as a function of the normalized radial distance from the inner radius $r_{d i m}$. At the beginning of the diffusion process important concentration gradients occur near the external surfaces. The permanent concentration (noticed perm in the caption) holds with a constant value because of the symmetrical hygroscopic loading. 
The macroscopic mechanical states were calculated for two types of composites structures: a unidirectionnaly reinforced cylinder, and a $\left[55^{\circ} /-55^{\circ}\right]_{S}$ laminated cylinder. Starting with the macroscopic stresses deduced from continuum mechanics, the local stresses in both the fiber and matrix were calculated either with the new analytical forms or the fully numerical model. The comparison between the two approaches is plotted on figure 2 which shows the obtained results for the central ply of a uni-directionnal composite whereas both the inner and central ply are considered in the case of the $[55 /-55]_{S}$ laminate.
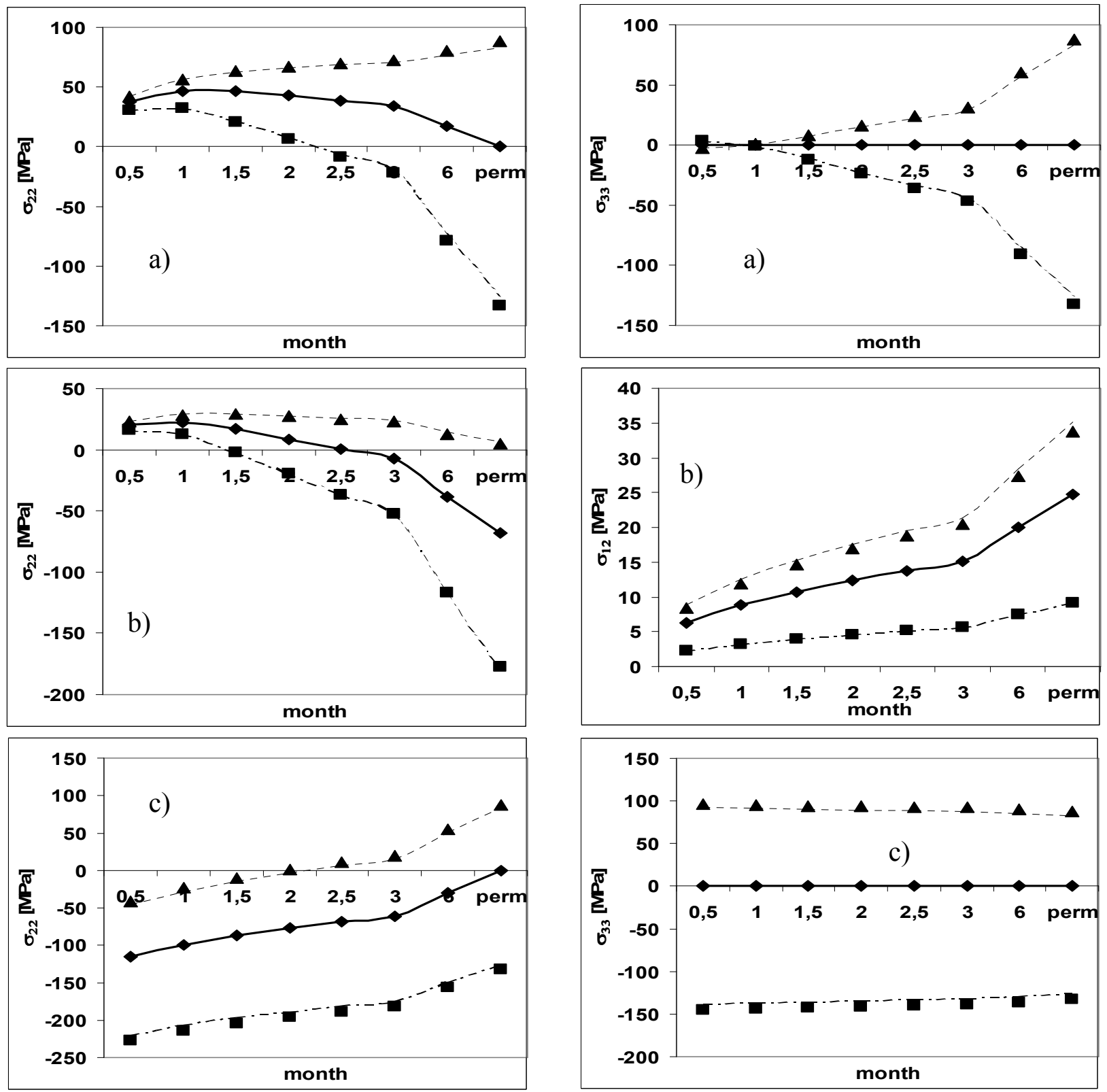

$\longrightarrow$ composite (CMF)

- matrix (numerical)

$\Delta \quad$ fiber (numerical)

$-\cdot-\cdot-$ matrix (analytical)

fiber (analytical)

Figure 2. Local stresses in T300/5208 composite for the central ply, in the case of a) the unidirectionaly reinforced composite and $b$ ) the $\left[+55^{\circ} /-55^{\circ}\right]_{S}$ symmetric laminate, whereas case $c$ ) depicts the stresses for the inner ply of a $\left[+55^{\circ} /-55^{\circ}\right]_{S}$ symmetric laminate.

CMF stands for Continuum Mechanics Formalisms. 
The graphs of figure 2 demonstrates the very good agreement between the numerical approach and the corresponding closed-forms solutions. The slight differences appearing are due to the small deviations on the components of Morris' tensor calculated using the two approaches.

4.3 Interpretation of the simulations. The highest level of macroscopic tensile stress is reached for the uni-directional composite, in the transverse direction and in the central ply of the structure (50 $\mathrm{MPa}$, cf. figure 2). The transverse stresses exceed probably the macroscopic tensile strength in this direction. The choice of a $\left[+55^{\circ} /-55^{\circ}\right]_{S}$ laminated allows to reduce the macroscopic stress in the transverse direction where the upper level fall down to $25 \mathrm{MPa}$. Nevertheless, a high shear stress rises along the time in the fibers of the central ply of such a structure $(35 \mathrm{MPa})$, and the matrix experiences strong compressive stresses that can reach -185 MPa in the studied example.

Moreover, the figure 2 shows that the micromechanical model always predict a very high compressive stress in the matrix of the inner ply whatever the laminate studied (the macroscopic stress is negligible in the normal direction because thin structures are considered). These local stresses could help to explain damage occurrence in the surface of composite structures submitted to such hygroscopic conditions.

\section{Conclusions and perspectives}

In the present work, a rigorous fully analytical treatment of the classical Kröner and Eshelby SelfConsistent model including morphology effects was achieved. Especially, the determination of Morris' tensor was performed in a satisfactory agreement with the transverse macroscopic elastic anisotropy expected for the fiber shape that should be taken into account in order to satisfactory represent the specific microstructure of carbon-fiber reinforced composites. The new closed-form solutions obtained for the components of Morris' tensor were introduced in the classical hygroelastic scale transition relation in order to express analytically the internal strains and stresses in both the fiber and the resin of a ply submitted to a hygro-elastic load. The closed-form solution demonstrated in the present work was compared to the fully numerical self-consistent model for various geometrical arrangements of the fibers: uni-directional or laminated composites.

A very good agreement is obtained between the two models for any component of the local stress tensors. It was also demonstrated that continuum mechanics and micromechanical models give complementary information about the occurrence of a possible damage during the loading of the structure.

In further work, the effects of a cyclical hygrothermal load on both the local and macroscopic mechanical states of carbon-fiber reinforced composites will be investigated.

\section{References}

[1] F. Jacquemin and A. Vautrin: Composite Structures Vol 58 (2002), pp. 1-9.

[2] J. D. Eshelby: Proceedings of the Royal Society London Vol A241 (1957), pp. 376-396.

[3] E. Kröner: Zeitschrift für Physik Vol 151, (1958), pp. 504-518.

[4] R. Hill: Journal of the Mechanics and Physics of Solids Vol 15, (1967), pp. 79-95.

[5] F. Jacquemin, S. Fréour and R. Guillén: JRPC Vol 24, (2005), pp. 485-502

[6] P. R. Morris: International Journal Engineering Science, Vol 8, (1970), pp. 49-61.

[7] R. J. Asaro and D. M. Barnett: JMPS, Vol 23, (1975) pp. 77-83.

[8] U. F. Kocks, C. N. Tomé, H. R. Wenk: Texture and Anisotropy, (Cambridge University Press 1998).

[9] T. Mura: Micromechanics of Defects in Solids, (Martinus Nijhoff Publishers, The Hague, Netherlands 1982).

[10] Y. P. Qiu, G. J. Weng : Int. J. of Solids and Structures, Vol 27, (1991) pp. 1537-1550. 